\title{
Experimental survey of the pressure cone and temperature field of an $\mathrm{A} / \mathrm{T}$ missile system
}

\author{
K. Krallis ${ }^{1}$, N. G. Orfanoudakis ${ }^{2}$, M. Founti ${ }^{3}$, D. T. Hountalas ${ }^{3}$, \\ A. Fatsis ${ }^{2}$ \& N. Vlachakis ${ }^{4}$ \\ ${ }^{1}$ Heron Consultant Engineers, Har. Trikoupi 107, 11473 Athens, Greece \\ ${ }^{2}$ Technical University of Chalkis, \\ Department of Mechanical Engineering, 34400 Chalkis, Greece \\ ${ }^{3}$ National Technical University of Athens, \\ Department of Mechanical Engineering, Zografou Campus, \\ Athens 15780, Greece \\ ${ }^{4}$ Engineering Science and Mechanics Department, \\ Virginia State University, USA
}

\begin{abstract}
This paper describes the characteristics of the temperature and pressure fields measured downstream of the launcher of the Russian "FAGOT" anti-tank missile system. The experimental data were used to establish the proper location of the launcher on a vehicle used by the Greek Army.

The pressure field developing at the rear of the missile launcher has the characteristics of a conical shock wave. The field was measured with an array of piezoelectric pressure transducers and a fast computer-based data acquisition system. The extent of the temperature field was established with high speed video and infra-red still photography and was confirmed with miniature thermocouple sensors.

The results showed that the pressure cone intersects the ground level at a distance of 1.5 to $2.5 \mathrm{~m}$ behind the launcher. Typical overpressure of the shock wave was of the order of 1 to 1.8 bar. The conical shock wave breaks down into several smaller shock waves at a distance of $3 \mathrm{~m}$ and extends up to $15 \mathrm{~m}$ behind the launcher. The diameter of the cone at this location is $2.5-3.0 \mathrm{~m}$.

Keywords: missile launcher, measurements, pressure field, temperature field.
\end{abstract}




\section{Introduction}

Most of existing information on the characteristics of the pressure cone and temperature field from missile systems is restricted and partially presented in International Symposia on Ballistics [1-5].

Temperature measurements at a $7.62 \mathrm{~mm}$ gun exit (muzzle flash) were performed under laboratory conditions by Klingenberg and Mach [1] using spectroscopy, absorption spectroscopy or high-speed photography with precalibrated film. Film techniques can be usually applied for field measurements, but should be used under low light conditions and with use of high-speed cameras.

Measurements of density and exit gas velocity in a $20 \mathrm{~mm}$ gun as presented in $[3,4]$, have been performed with the use of Schlieren photography and laser Doppler anemometry methods. Both the above methods have serious shortcomings in case that they are applied in larger than laboratory scale. The application of Schlieren and laser Doppler anemometry in field measurements is prohibitive due to high costs and inaccuracies induced by limitations of the methods themselves.

However, pressure measurements using piezoelectric transducers have been performed by Klingenberg and Schroder [2], Klingenberg [3] and Klingenberg et al. [4] with very good response, especially at the frequency of $20 \mathrm{~Hz}$. Pressure transducers are widely used for in cylinder measurements of internal combustion engines commercially available.

\section{Instrumentation and experimental method}

The work reported here has two major parts: the first refers to flow visualisation with the use of photography and the latter to pressure and temperature measurements.

Various types of equipment have been used for the visualisation of the flow field developing at the rear of the launcher during launching conditions. High speed (24 frames/sec), high-resolution S-VHS video cameras allowed fast, real time recording of the phenomena. In addition, three professional SLR-cameras have been used: one panoramic Linhof 612, one Technorama, one EOS $1 \mathrm{~N}$ and one high resolution EOS 1NRS. The cameras were equipped with motor drives and zoom lenses of $28-70 \mathrm{~mm}, \mathrm{~F} 2.8 \mathrm{~L}$ and $35-70 \mathrm{~mm}, \mathrm{~F} 3.5-\mathrm{F} 5.6$. During preliminary launches, amateur SLR-cameras with 100 ASA and infra-red films have been used to allow for representation of the different temperature zones. The flow field was seeded with $0-0.3 \mathrm{~mm}$ diameter, lightweight (density equal to $60 \mathrm{~kg} / \mathrm{m}^{3}$ ), expanded perlite particles that could travel together with the exhaust gases at the tail end of the missile launcher. Perlite had been chosen to support the flow visualisation because is light and inert, as well as environmentalfriendly.

The pressure and temperature measurements have been performed with piezoelectric transducers and thermocouples, respectively. They have been mounted in selected positions on a specially designed and constructed metallic 
frame, placed downstream of the gas exit of the launcher. The research team has designed the measuring system and has calibrated the measuring equipment and the necessary data acquisition system. The metallic frame has been constructed by 301 Technical Corps Unit of the Greek Army.

In order to allow adequate representation of the pressure cone characteristics and at the same time to reduce the initial cost of the measurements, it was decided to use 5 transducers located axially and radially, at critical points, with respect to the launcher. It has been assumed that the pressure and temperature cones develop axi-symmetrically downstream the tail edge of the missile launcher.

The signals from the piezoelectric transducers were amplified and together with the signals from the thermocouples were recorded using two independent data acquisition systems in order to avoid repetition of the costly measurements (i.e. launching of a FAGOT missile) associated with failure of the data acquisition systems.

Table 1: Characteristics of the measuring system.

\begin{tabular}{|c|c|c|}
\hline $\begin{array}{ll}\text { Type } & \text { of } \\
\text { Equipment }\end{array}$ & Parameter & Typical Characteristics \\
\hline $\begin{array}{l}\text { Pressure } \\
\text { transducers: } \\
\text { Kistler } \\
\text { Piezotron } \\
\text { Tranducer } \\
\end{array}$ & $\begin{array}{l}\text { Operation limit } \\
\text { Sensitivity } \\
\text { Eigen frequency } \\
\text { linearity }\end{array}$ & $\begin{array}{l}0-20 \text { bar or } 0-200 \text { bar } \\
25 \mathrm{mV} / \mathrm{bar} \\
>50 \mathrm{KHz} \\
<1 \% \mathrm{FSO}\end{array}$ \\
\hline $\begin{array}{l}\text { Pressure } \\
\text { transducers' } \\
\text { amplifier: } \\
\text { Kistler }\end{array}$ & $\begin{array}{l}\text { Nominal current } \\
\text { Max. signal voltage } \\
\text { Amplification } \\
\text { Frequency response }+5 \% \\
\text { (at } 1 \text { meg load \& } 10 \mathrm{Vpp} \text { ) } \\
\text { Max. Signal Voltage } \\
\text { Curent } \\
\text { Impedance } \\
\text { Noise }\end{array}$ & $\begin{array}{l}2 \ldots 18 \mathrm{~mA} \\
20 \mathrm{Vpp} \\
0.5 \ldots 5 \\
\text { from } \mathrm{DC} \text { to } 220 \mathrm{KHz} \\
20 \mathrm{Vpp} \text { for unit amplification } \\
+10 \mathrm{~mA} \\
20 \Omega \\
250 \mu \text { for unit amplification }\end{array}$ \\
\hline $\begin{array}{l}\text { Analog-digital } \\
\text { converter }\end{array}$ & $\begin{array}{l}\text { Sampling frequency } \\
\text { Number of analogue } \\
\text { inputs } \\
\text { Input Voltage } \\
\text { Amplification } \\
\text { Input Impedance } \\
\text { Resolution } \\
\text { Differential non linearity } \\
\text { System accuracy }\end{array}$ & $\begin{array}{l}100 \mathrm{KHz} \\
16 \text { single inputs, } 8 \text { differential } \\
+10 \text { Volt } \\
1,2,4 \\
100 \mathrm{Megohms}, 10 \mathrm{pF} \text { (channel } \\
\text { OFF) } \\
100 \mathrm{Megohms}, 10 \mathrm{pF} \text { (channel } \\
\text { ON) } \\
12 \text { Bit } \\
<1 \mathrm{LSB} \\
+0.05 \mathrm{FSR}\end{array}$ \\
\hline
\end{tabular}


The data acquisition frequency was 1 and $2 \mathrm{kHz}$, established by literature review [1-4] and the signal cables were shielded to avoid noise and interference. For each launch 16000 data points have been recorded and stored. The electricity supply was provided by a military diesel generator, which in turn was connected to an UPS (uninterrupted power system), to avoid power surges. The characteristics of the pressure transducers, of the amplifiers and the data acquisition system used for the measurements, are shown in Table 1.

Two very sensitive thermocouples $(\Phi 5 \mu \mathrm{m})$, with high response to temperature variations, were placed close to the gas exit and on the axis of symmetry. The thermocouples were installed on an old-used carrier. The temperature measured was actually the temperature of the carrier and not of the gases. Nevertheless, it is strongly connected to that of the gas, if the gas density and thermal conductivity, the heat transfer coefficient (from gas to thermocouple) and the thermal conductivity of the thermocouple are considered. The temperature measurements were recorded simultaneously with the pressure data using the same data acquisition system, as described above.

There was generally a problem to synchronise the cameras and the instruments with the launcher itself because there was always a 1-1.5 s lag between triggering and launching. Installation of an external triggering adapter was not possible due to lack of technical information in relation to the launcher and the missile. Triggering of the cameras and of the data acquisition system was done manually.

During the last group of measurements, four launches have been conducted and data recording had started well before and stopped well after the completion of the phenomenon, to allow optimum data analysis.

\section{Results}

\subsection{Flow visualisation and photographic work}

Preliminary determination of the pressure cone had been conducted by use of the photographic material collected during preliminary and main launches. The pressure, temperature measurements and the flow visualisation were, at most times, conducted simultaneously. This assisted the extraction of conclusions and comparison of the photographic and measurement data

Flow visualisation allowed initial determination of the angle of launching and pressure cone. Expanded perlite of low density $\left(60 \mathrm{~kg} / \mathrm{m}^{3}\right)$ has been used to fill the half section of a $\Phi 120 \mathrm{~mm}$ and $1.5 \mathrm{~m}$ long pipe, which in turn had been placed on the ground at the back of the launcher. Vertical staffs with red markings have been positioned every meter and allowed quick estimation of the cone height. The missile and the long pipe filled with expanded perlite particles are shown in Figure 1. It can be clearly seen that milliseconds (in fact $5 \mathrm{~ms}$ ) after launching the pipe broke into pieces exactly at the point where the shock wave intersected the ground level. At this location the perlite particles got elevated due to the exerted pressure forces and thereafter followed the exhaust gas path-lines. A series of such photographs (e.g. Figure 2) allowed visual determination of the 
pressure cone length and height, when launching is from the ground. Figure 1, also shows red-hot smithereens that ejected during and due to the launch flying along the pressure cone.

The results from processing the photographic material can be summarized as shown in Table 2.

Flow visualisation and photography were used to interpret the phenomena and to verify the pressure transducer and thermocouple results. Photographic work has served to establish the following:

The angle of the thermal and pressure cone are not strongly dependent on the angle the launcher forms with the ground.

The 'front flame' (i.e. the flame formed at the direction of the fly of the A/T missile) has a conical shape; it is ca. $0.4-0.9 \mathrm{~m}$ long, with diameter ca. $0.3-$ $0.5 \mathrm{~m}$.

The pressure cone attains characteristics of intense turbulence mixing downstream the first $3 \mathrm{~m}$ from the gas exit. The cone has about $15 \mathrm{~m}$ length and 2.5 to $3 \mathrm{~m}$ height.

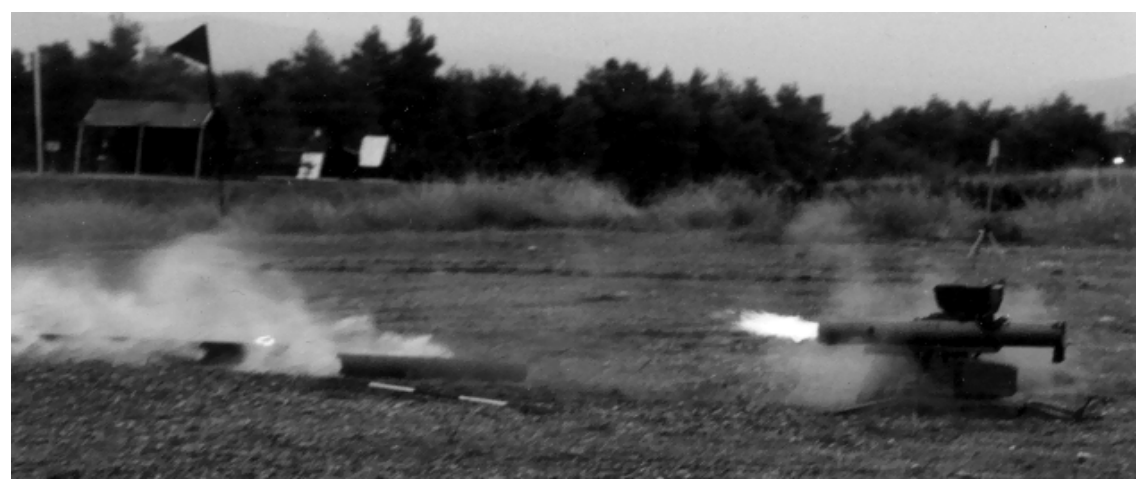

Figure 1: Visualisation of the pressure cone at the rear of the launcher.

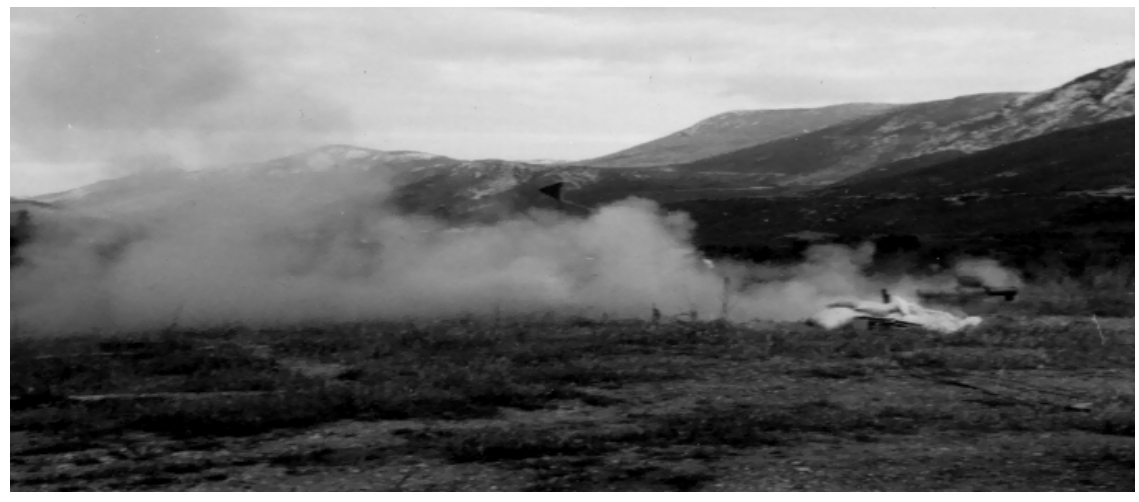

Figure 2: Long distance view of the visualised pressure cone at the rear of the launcher. 
Table 2.

Geometry of the gunshot

Height of the launcher from ground

Angle of launching

Mean flight velocity

Measurements

Area of max. ground pressure

Area of max. temperatures

Pressure cone downstream of the gas exit

$40 \mathrm{~cm}$

$5^{0}$

$180 \mathrm{~m} / \mathrm{s}$

Thermal cone downstream of the gas length $0.9 \mathrm{~m}$, diameter $0.6-1.0 \mathrm{~m}$ exit

High light intensity Cone upstream length $0.4-0.9 \mathrm{~m}$, diameter $0.3-$ of the launcher

$2.0-2.5 \mathrm{~m}$ downstream the gas exit

$0.9-1.2 \mathrm{~m}$ downstream the gas exit

length ca. $12-15 \mathrm{~m}$, height ca. $2.5-$

$3 \mathrm{~m}$.

$0.5 \mathrm{~m}$

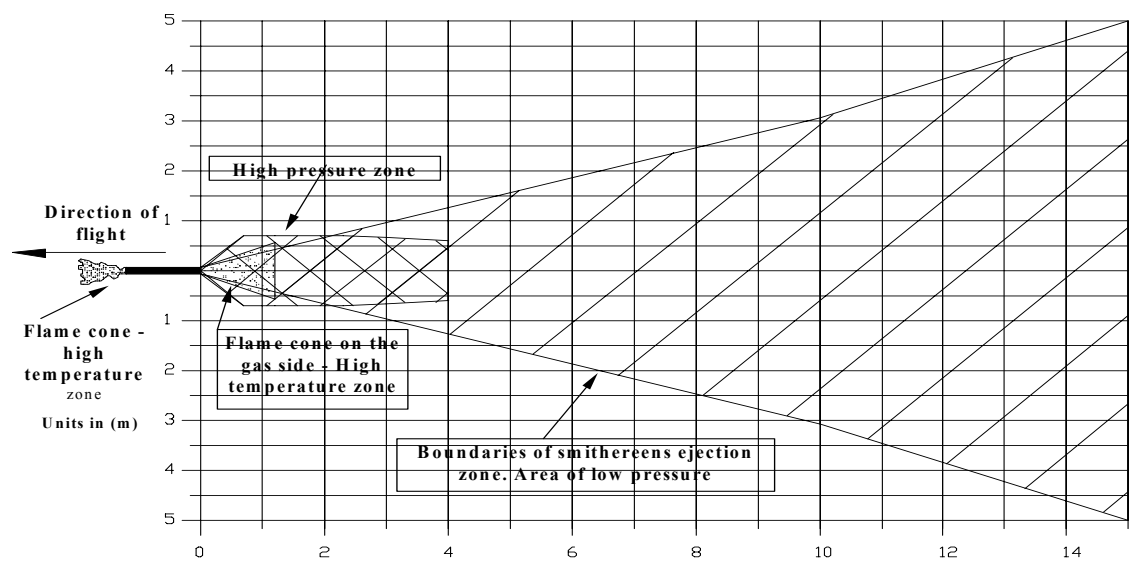

Figure 3: Determination of danger zones during the launch of the FAGOT A/T missile system.

The process of the flow visualisation showed that the angle, of the pressure cone with the ground is about $9^{\circ}$.

Based on the photographic and experimental data Figure 3 was drawn in order to designate safe angles of launching (for personnel and vehicles). In this figure, the most important characteristics of the pressure and thermal cone are defined. In addition, areas where smithereens were ejected during and due to the launch are also designated.

\subsection{Pressure and temperature measurements}

The measurements of temperature and pressure are shown in Figures 4-6. For each measurement campaign, five different pressure transducers were used. Figure 4 represents the evolution of pressure and temperature with time for various positions of the transducers. 

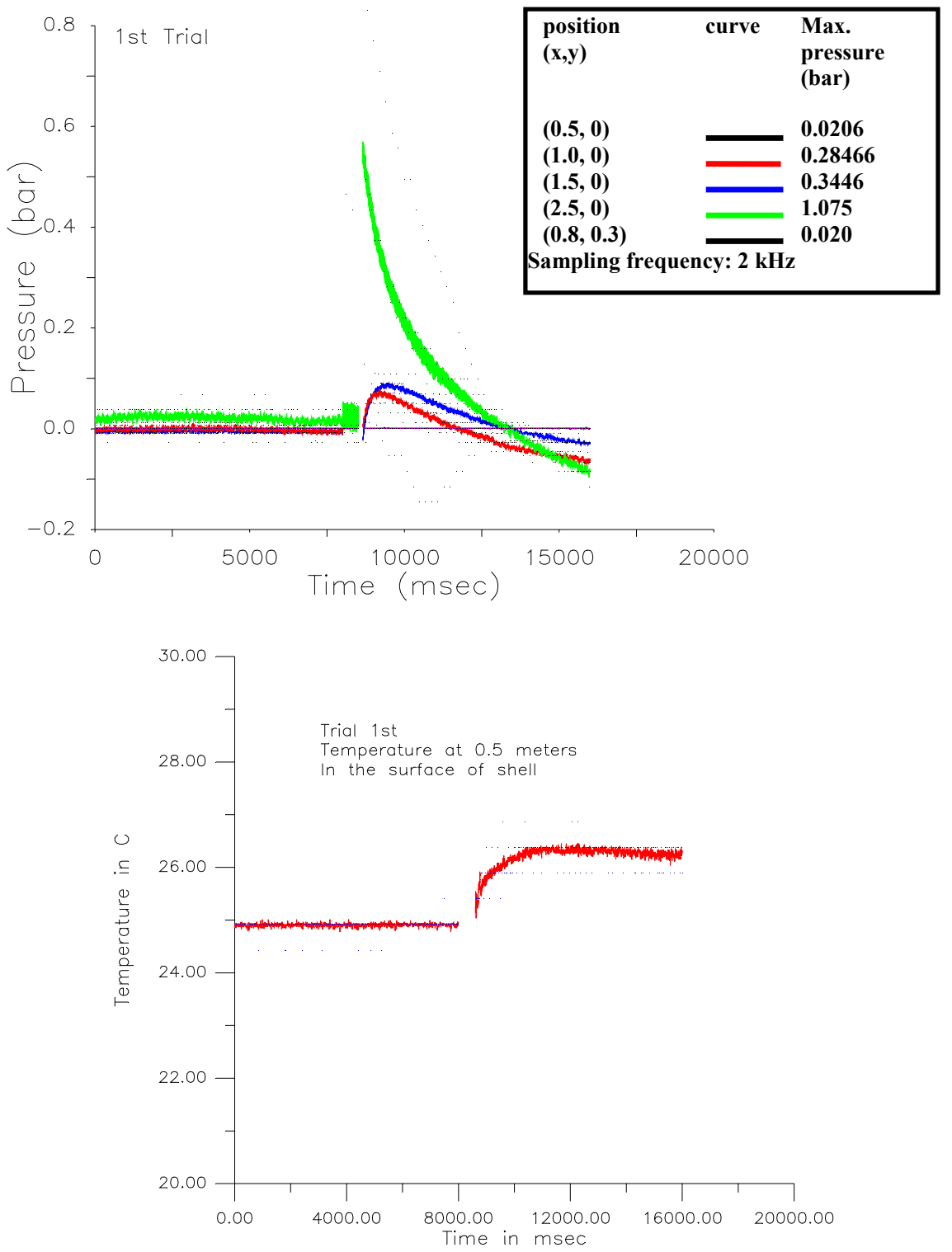

Figure 4: Variation of pressure (above) and temperature (below) at various positions downstream the launcher.

Based on the maximum-recorded pressure at each known position of the pressure transducers the variation of maximum pressure with spatial location is plotted in Figures 5 and 6. 


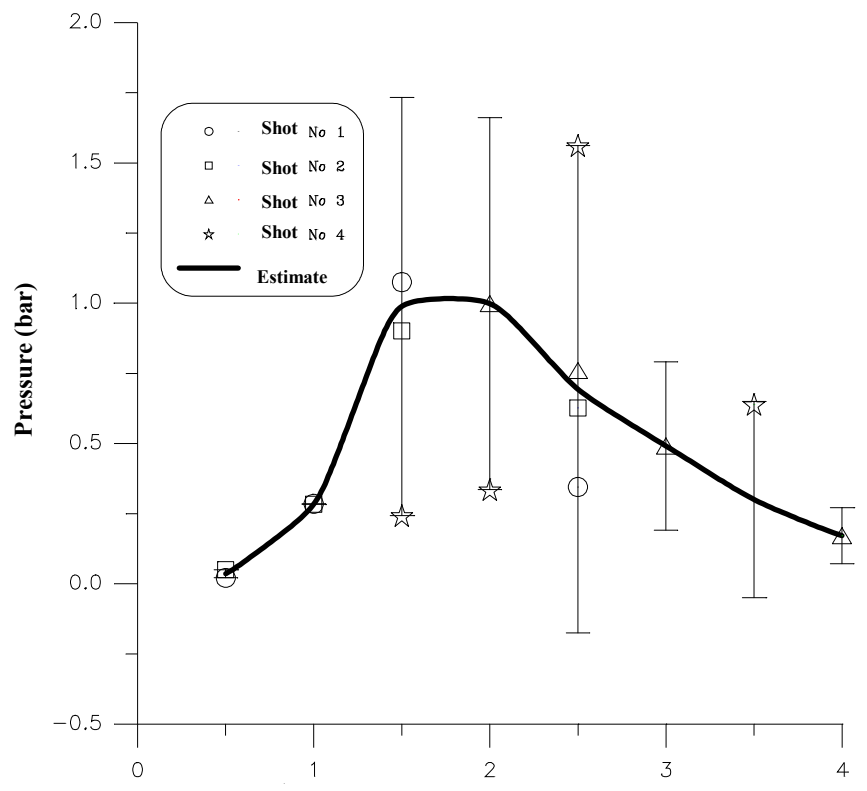

Distance from launcher on the ground (m)

Figure 5: Variation of maximum pressure along the axis of the launcher, which was positioned at $50 \mathrm{~cm}$ from the ground.

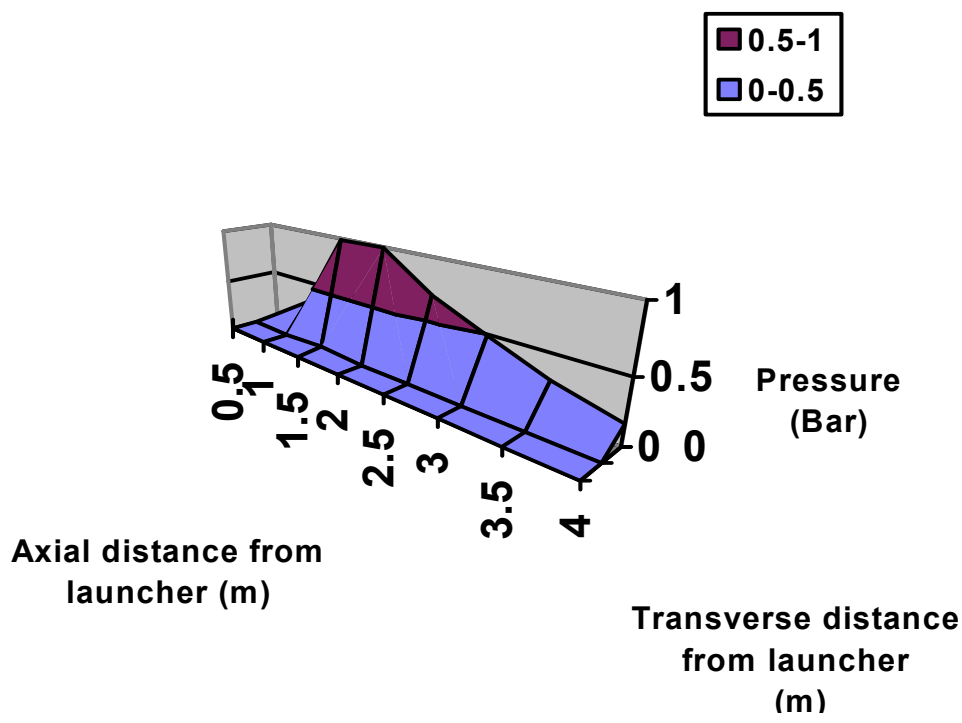

Figure 6: Constant pressure lines for launcher position at $50 \mathrm{~cm}$ from ground. 
Figure 5 demonstrates that the maximum value of the pressure occurs in a range between 1.5 and $2 \mathrm{~m}$ downstream of the gas exit. This statement is in agreement with the photographic results. The maximum measured pressure value was $1 \pm 0.8$ bar. This value is expected to vary with the change of the height of launcher from the ground (as for example, when the launcher would be installed on the military vehicle). Figure 6 shows the lines of constant pressure downstream of the gas exit, for launcher position at height $50 \mathrm{~cm}$ from the ground. This figure is representative for the installed height of the launcher.

\section{Conclusions}

This paper described the tasks undertaken to investigate the temperature and pressure fields behind the launcher of the Russian "Fagot" anti-tank missile system. The measurements were conducted in order to allow decision about the proper location of the launcher on a vehicle used by the Greek Army. The main conclusions can be summarised, for launch position at $50 \mathrm{~cm}$ height from the ground, as follows:

The pressure and thermal cone have characteristics independent from the angle of launching.

Flame is generated at both sides of launcher; the characteristics of these flames are strongly dependent on the kind of the launch (successful and not).

The maximum measured pressure on the ground was found to be at distance between 1.5 and $2.5 \mathrm{~m}$ downstream of the gas exit and it found to be $1 \pm 0.8 \mathrm{bar}$.

The pressure cone is extended $15 \mathrm{~m}$ downstream the gas exit, at a height of $2.5-3 \mathrm{~m}$, has turbulent characteristics.

The angle between the cone and the ground is about $9^{\circ}$.

The installation of the $\mathrm{A} / \mathrm{T}$ launcher on a vehicle is safe under certain conditions.

\section{References}

[1] Klingenberg, G. and Mach, H.: "Investigation of Combustion Phenomena associated with the flow of Hot Propellant Gases - I: Spectroscopic Temperature Measurements Inside the Muzzle Flash of a Rifle", Combustion and Flame, 27, pp. 163-176, 1976

[2] Klingenberg, G. and Schroder, G.A.: "Investigation of Combustion Phenomena associated with the flow of Hot Propellant Gases - II: Gas Velocity Measurements by Laser Induced Gas Breakdown", Combustion and Flame, 27, pp. 177-187, 1976.

[3] Klingenberg, G.: "Investigation of Combustion Phenomena associated with the flow of Hot Propellant Gases - III: Experimental Survey of the Formation and Decay of Muzzle Flow Fields and of Pressure Measurements", Combustion and Flame, 29, pp. 289-309, 1977.

[4] Klingenberg, G., Mach, H. and Smeets, G.: "Flow Field Measurements of an Unsteady Reacting Muzzle Exhaust Flow", Transactions of ASME, 105, pp 884-888, 1983. 
150 Computational Ballistics III

[5] Stiefel, L., Editor: "Gun Propulsion Technology”, American Institute of Astronautics and Aeronautics, Progress in Astronautics and Aeronautics, 109, AIAA, Washington 1988. 